\title{
A survey of Canadian gastroenterologists about the management of Barrett's esophagus
}

\author{
Lisa MacNeil-Covin BSc ${ }^{1}$, Alan G Casson MB ChB MSc FRCSC FACS², Dickran Malatjalian MD $^{3}$, \\ Sander Veldhuyzen van Zanten MD PhD FRCPC ${ }^{4}$
}

\begin{abstract}
L MacNeil-Covin, AG Casson, D Malatjalian, S Veldhuyzen van Zanten. A survey of Canadian gastroenterologists about the management of Barrett's esophagus. Can J Gastroenterol $2003 ; 17(5): 313-317$.
\end{abstract}

The aims of the present study were to determine practice patterns of Canadian gastroenterologists for screening patients with Barrett's esophagus and to compare current practice patterns with published guidelines. A secondary goal was to evaluate whether gastroenterologists recommend a 'once in a lifetime' endoscopy for patients with chronic gastroesophageal reflux disease. A structured questionnaire regarding screening for Barrett's esophagus was sent to members of the Canadian Association of Gastroenterology. The overall response rate was $51 \%$ (203 of 396). Of the 203 respondents, 165 (81\%) performed endoscopies in adults and form the basis of this report. The majority of Canadian gastroenterologists followed published guidelines, with $62 \%$ screening patients without dysplasia every two years. Patients with low grade dysplasia were screened more frequently, with $54 \%$ of respondents performing endoscopy every six months, and $35 \%$ on a yearly basis. Biopsy protocols showed the greatest variation, with $46 \%$ of gastroenterologists taking four-quadrant biopsies at $2 \mathrm{~cm}$ intervals along the columnar-lined (Barrett's) esophagus. Seventy-six per cent of gastroenterologists agreed that all patients with chronic gastroesophageal reflux should have a 'once in a lifetime' endoscopy to screen for Barrett's esophagus. The majority of Canadian gastroenterologists follow current guidelines for the management of Barrett's esophagus and support the concept of 'once in a lifetime' endoscopy.

Key Words: Barrett's esophagus; Canada; Dysplasia; Gastroesophageal reflux disease; Screening; Survey

\section{Enquête auprès des gastro-entérologues canadiens sur le traitement de l'œsophage de Barrett}

\begin{abstract}
Cette enquête visait à déterminer les modèles de pratique des gastroentérologues canadiens pour le dépistage de l'œsophage de Barrett ainsi qu'à comparer les modèles actuels de pratique avec les lignes directrices publiées. Son objectif secondaire était de déterminer si les gastro-entérologues recommandent une « seule endoscopie à vie " chez les patients qui souffrent de reflux gastro-oesophagien chronique. Un questionnaire structuré sur le dépistage de l'œesophage de Barrett a été envoyé aux membres de l'Association canadienne de gastro-entérologie. Le taux de réponse global a été de 51 \% (203 sur 396). Parmi les 203 répondants, 165 (81\%) effectuent des endoscopies chez des adultes et ce sont eux qui ont servi de base à ce rapport. La majorité des gastro-entérologues canadiens respectent les lignes directrices émises, et 62 \% d'entre eux effectuent un test de dépistage tous les deux ans chez des patients ne présentant pas de dysplasie. Les patients qui présentent une légère dysplasie sont examinés plus fréquemment; à cet égard, $54 \%$ des répondants prescrivent à ces patients une endoscopie tous les six mois et $35 \%$, une endoscopie par année. Les protocoles de biopsie ont montré de grandes différences alors que $46 \%$ des gastro-entérologues effectuent des biopsies sur les quatre faces de l'œsophage, à intervalles de $2 \mathrm{~cm}$ le long de l'endobrachyœsophage (œsophage de Barrett). Au total, $76 \%$ des gastro-entérologues reconnaissent que tous les patients souffrant de reflux gastro-oesophagien chronique devrait subir une endoscopie au cours de leur vie dans le but de dépister l'œesophage de Barrett. La majorité des gastro-entérologues suivent les lignes directrices émises pour le traitement de l'œsophage de Barrett et appuient le concept de l'endoscopie une fois dans sa vie.
\end{abstract}

B arrett's esophagus (BE) is a premalignant condition characterized by replacement of squamous epithelium of the esophagus with specialized intestinal columnar epithelium. The development of BE is associated with chronic gastroesophageal reflux disease (GERD) $(1,2)$. The prevalence of BE is estimated at 22.6 cases in 100,000 population, based on cases detected in patients undergoing esophagogastroscopy (endoscopy) (3). However, the results of 733 unselected autopsies estimated the actual prevalence to be much higher in the general population, at 376 per 100,000 (3). The prevalence of $\mathrm{BE}$ is threefold higher in male patients compared with females (4). It is generally accepted that BE carries a small but definite risk of progression to invasive esophageal adenocarcinoma, that is estimated from one in 52 to one in 208 patient years follow-up (5-9) or $0.5 \%$ per year (4). However, a recent report suggests a publication bias exists in reporting of cancer risk, consequently overestimating risk (10).

Over the past 30 years the incidence of primary esophageal adenocarcinoma has increased steadily (4), especially in white males $(4,11,12)$. The prognosis for invasive esophageal adenocarcinoma is poor, and despite advances in multimodality therapy, five-year survival generally remains below 10\% (13). However, in selected surgical series, overall five-year survival may approach $30 \%$ following resection of early stage disease $(14,15)$, or for tumours with favourable biology (16). This observation underlies the rationale for endoscopic surveillance

\footnotetext{
${ }^{1}$ Medical student; ${ }^{2}$ Department of Surgery; ${ }^{3}$ Division of Anatomical Pathology; ${ }^{4}$ Division of Gastroenterology, Dalhousie University, Halifax, Nova Scotia

Correspondence: Dr Sander Veldhuyzen van Zanten, Dalhousie University, Division of Gastroenterology, Room 928, Centennial Building, Victoria General Site, Queen Elizabeth II Health Sciences Centre, Halifax, Nova Scotia B4H 2Y9. Telephone 902-473-1499, fax 902-473-5548, e-mail zanten@is.dal.ca
}

Received for publication October 18, 2002. Accepted February 12, 2003 
(17), with the hope that early detection will improve long term survival. Currently, there is consensus that patients diagnosed with BE should enter an endoscopic surveillance program. However, the optimal frequency with which endoscopy and biopsy should be repeated is not known.

A number of guidelines for managing BE have been proposed (Table 1), with the following considerations: frequency of surveillance for patients with BE without dysplasia, and for low grade and high grade dysplasia; the timing of surgical referral; the role of alternative therapies; and standardization of biopsy protocols (18-21). None of these guidelines is based on prospective randomized studies.

The aim of the present study was to determine practice patterns of Canadian gastroenterologists for screening patients with $\mathrm{BE}$ and to compare those results with the published guidelines. A secondary objective was to determine whether gastroenterologists perform a 'once in a lifetime' endoscopy in patients who have long standing GERD.

\section{METHODS}

A two-page survey was developed, pretested using five gastroenterologists, and mailed with a self-addressed return envelope to active members of the Canadian Association of Gastroenterologists (CAG). The survey focused on endoscopic surveillance practices for patients with BE without dysplasia, with low grade dysplasia and with high grade dysplasia. Physicians were also asked about their biopsy techniques and whether they support a 'once in a lifetime' endoscopy for patients with chronic GERD. Surveys were sent out in English only. The survey was anonymous and included the following questions: practice setting (university or community); number of years in practice; and the number of patients seen with high grade dysplasia and esophageal adenocarcinoma. Physicians were asked to complete the survey without having to rely on patient charts. In the analysis the proportion of respondents who followed recommended guidelines is reported.

\section{RESULTS}

Surveys were mailed to 476 members of the CAG. From 80 surveys, it could not be determined whether the CAG members were in active clinical practice, which left 396 possible responders. It is estimated that at least $25 \%$ of CAG members are nonphysicians but the database does not contain that information. A total of 203 (51\%) surveys were returned. One hundred sixty-five of the 203 responders were practising gastroenterologists, and their responses were used in the analysis. If nonphysician CAG members are excluded the response rate is $65 \%$ (203 of 297). Of the 38 excluded from analysis, 18 responders were pediatric gastroenterologists not dealing with $\mathrm{BE}$, eight did not perform endoscopy, seven were retired, three were full-time researchers, one was a radiologist and one was a surgeon who did not perform endoscopy. Of the 165 responders 52 (32\%) were from Western Canada (British Columbia, Alberta, Manitoba, Saskatchewan), 67 were from Ontario (41\%), 25 were from Quebec (15\%), 20 were from Eastern Canada (12\%) (Newfoundland, Prince Edward Island, Nova Scotia, New Brunswick) and three (1\%) were from an unknown location.

\section{Physician characteristics}

The number of years in practice was distributed as follows (Table 2): $31 \%$ less than 10 years, 33\% 11 to 20 years and $35 \%$ greater than 20 years. Fifty per cent of gastroenterologists were in community practice, and the remaining $50 \%$ indicated they had either full-time or part-time university-based practices. Most of the respondents (82\%) indicated they see more than five patients with BE every year. When asked about the total number of patients with BE with high grade dysplasia seen over the course of their practice, most of the respondents (85\%) indicated they had seen less than five cases. Similarly, the number of esophageal adenocarcinomas seen by physicians was also reported to be low. Dividing the estimated number of cancer cases by the number of years in practice, it can be estimated that physicians see on average one patient with esophageal adenocarcinoma each year.

\section{Endoscopic surveillance intervals}

Surveillance intervals varied depending on whether patients with BE had no, low grade or high grade dysplasia (Table 3). For patients with BE without dysplasia, $62 \%$ of gastroenterologists indicated they would perform endoscopy every two years; $19 \%$ indicated they would perform yearly endoscopy and the remaining $19 \%$ at intervals every three years or greater. The frequency of surveillance for patients with low grade dysplasia was reported to be six-monthly (55\%), yearly (35\%), or less than six months (10\%). For patients with high grade dysplasia, 56 gastroenterologists reported they would continue surveillance with a frequency of every three months or less $(70 \%)$, or every six months $(30 \%)$.

TABLE 1

Current practice guidelines for the screening of Barrett's esophagus

\begin{tabular}{|c|c|c|c|c|c|}
\hline Guidelines (reference) & Date & No dysplasia & $\begin{array}{l}\text { Endoscopy intervals } \\
\text { Low grade dysplasia }\end{array}$ & High grade dysplasia & Biopsy protocol ${ }^{\star}$ \\
\hline SFED guidelines (20) & 2000 & $\begin{array}{l}>3 \mathrm{~cm} \text { : two years } \\
<3 \mathrm{~cm} \text { : three years }\end{array}$ & $\begin{array}{l}\text { every six months } \\
\text { for one year }\end{array}$ & $\begin{array}{l}\text { two pathologists confirm, then } \\
\text { surgery or alternative therapy }\end{array}$ & $\begin{array}{l}\text { four quadrants: } \\
\qquad \begin{array}{l}>3 \mathrm{~cm} \text {, q } 2 \mathrm{~cm} \\
<3 \mathrm{~cm} \text {, q } 1 \mathrm{~cm}\end{array}\end{array}$ \\
\hline ACG guidelines (18) & 1998 & two to three years & $\begin{array}{l}\text { six month intervals } \\
\text { (twice) then at one year }\end{array}$ & $\begin{array}{l}\text { esophagectomy or } \\
\text { alternative therapy }\end{array}$ & $\begin{array}{l}\text { four quadrants: } \\
\text { q } 2 \mathrm{~cm} \text {, and } \\
\text { abnormalities }\end{array}$ \\
\hline Canadian Consensus (19) & 1997 & two years & three to six months & $\begin{array}{l}\text { esophagectomy or } \\
\text { three month surveillance }\end{array}$ & $\begin{array}{l}\text { four quadrants, } \\
\text { q } 2 \mathrm{~cm}\end{array}$ \\
\hline Provenzale et al (21) & 1994 & two to three years & \multicolumn{3}{|c|}{$\uparrow$ survival highest quality-adjusted life expectancy } \\
\hline Computer cohort & & five years & \multicolumn{3}{|c|}{$\uparrow$ life expectancy similar to common medical intervention } \\
\hline
\end{tabular}

*Biopsies taken from all 4 quadrants. This technique was repeated every 1 or $2 \mathrm{~cm}$ along the length of Barrett's Esophagus ( $1 \mathrm{~cm}, 2 \mathrm{~cm})$. Symbols ( $<3 \mathrm{~cm},>3 \mathrm{~cm}$ ) refer to the visible length of Barrett's Esophagus. ACG American College of Gastroenterology; SFED French Society of Digestive Endoscopy. NOTE: The ACG guidelines have recently been updated (27). They do not specify the initial interval of endoscopies after the diagnosis Barrett's esophagus is made. The updated guideline states that the screening interval can be increased to three years after two consecutive endoscopies did not detect dyspepsia 
TABLE 2

Characteristics of respondents

\begin{tabular}{lc}
\hline Survey question & $\begin{array}{l}\text { Number of } \\
\text { respondents (\%) }\end{array}$ \\
\hline $\begin{array}{l}\text { Number of years in practice } \\
<10\end{array}$ & 50 of $163(31)$ \\
$11-21$ & 50 of $163(31)$ \\
$21-30$ & 52 of $163(32)$ \\
$>31$ & 11 of $163(7)$ \\
Type of practice & \\
Community-based & 83 of $165(50)$ \\
Full-time university (academic) & 56 of $165(34)$ \\
Part-time university & 26 of $165(16)$ \\
Number of patients with Barrett's esophagus they see per year \\
$<5$ & 29 of $165(18)$ \\
$6-10$ & 55 of $165(33)$ \\
$11-20$ & 42 of $165(25)$ \\
$21-30$ & 18 of $165(11)$ \\
$>31$ & 11 of $165(13)$ \\
Number of patients ever seen with high grade & dysplasia \\
$<5$ & 140 of $164(85)$ \\
$6-10$ & 18 of $164(11)$ \\
$>11$ & 6 of $164(5)$ \\
Number of patients ever seen with esophageal adenocarcinoma & 31 of $165(19)$ \\
$<5$ & 22 of $165(13)$ \\
$6-10$ & 43 of $165(26)$ \\
$11-20$ & 18 of $165(11)$ \\
$21-30$ & 20 of $165(12)$ \\
$31-40$ & 11 of $165(7)$ \\
$41-50$ & 20 of $165(12)$ \\
$>50$ & \\
\hline
\end{tabular}

Management of patients with high grade dysplasia

Three selections were given in the survey for the management of patients with high grade dysplasia: continued surveillance, esophageal resection or other (alternative) therapy. As responders were able to check multiple options there is overlap for the following percentages. However, most respondents indicated a preference for esophageal resection $(81 \%)$, followed by continued surveillance (34\%), and other therapies, such as mucosal ablation, laser or photodynamic therapy (32\%); $20 \%$ would consider all three options.

\section{Endoscopic biopsy techniques}

Most gastroenterologists (71\%) indicated they used the fourquadrant biopsy technique, but differed on the length of columnar-lined esophagus biopsied (Table 4): $1 \mathrm{~cm}$ intervals (13\%); 2 $\mathrm{cm}$ intervals (46\%); greater than $3 \mathrm{~cm}$ intervals (7\%); and no specified intervals $(5 \%)$. Fifteen per cent of respondents indicated they did not adhere to a defined biopsy protocol.

\section{'Once in a lifetime' endoscopy for patients with chronic GERD}

This component of the survey posed two questions about 'once in a lifetime' endoscopy for patients with chronic GERD (Table 5). Seventy-six per cent of gastroenterologists indicated support for 'once in a lifetime' endoscopy. In response to the second question about criteria used to determine when a person should have the endoscopy, $61 \%$ indicated duration of symptoms (greater than five years); $40 \%$ said they would use age (greater than 50 years); and 33\% indicated other criteria, including medication use.

\section{DISCUSSION}

The present survey found that Canadian gastroenterologists regularly perform endoscopic surveillance of patients with $\mathrm{BE}$, and the majority follow published guidelines (18-21). Comparable surveys have been performed in other countries with similar results (22-25). All reported that the majority of physicians follow published guidelines, but found considerable variation with surveillance interval and biopsy protocols.

In the present survey, the majority of respondents (62\%) carried out endoscopic surveillance every two years for patients with BE without dysplasia, as recommended by Canadian guidelines (19), although 19\% of respondents performed yearly screening. Given the low potential for cancer progression in patients with $\mathrm{BE}$, adhering to the published guidelines would likely result in substantial savings to the Canadian health care system. Furthermore, recent data suggest that the screening interval perhaps can be increased to three years if dysplasia is not seen at two endoscopic intervals (26).

The American College of Gastroenterology (ACG) recommends that surveillance endoscopies are performed in patients in whom a diagnosis of Barrett's esophagus is made (18). However, the guidelines are vague in that they do not state the screening interval. Recently, the ACG guidelines have been updated (27). They still do not specify an initial screening interval after the diagnosis of Barrett's esophagus is made. However, the new guidelines state that the interval can be three years after two consecutive endosocopies that did not find any evidence of dysplasia on histology. The present survey was conducted before the updated guidelines were published. At the moment the recommendations for screening intervals are being evaluated. It seems likely that in the future the screening intervals will increase in patients who have no evidence of dysplasia. It is interesting that the guidelines do not take ethnicity into account. It is well established that especially white males are at the highest risk for developing Barrett's esophagus.

There are no prospective randomized controlled clinical trials to help determine the optimal endoscopic interval. Current guidelines (18-21) base their recommendations on cohort and retrospective studies. Yearly endoscopic screenings

TABLE 3

Endoscopic surveillance intervals used in the physicians' practices*

\begin{tabular}{|c|c|c|c|c|c|}
\hline BE with no dysplasia & n (\%) & BE with LDG & n (\%) & BE with HDG & n (\%) \\
\hline One year & 31 of $165(19)$ & Less than five months & 11 of $152(7.2)$ & Less than three months & 39 of $56(70)$ \\
\hline Two years & 103 of $165(62)$ & Six months & 83 of $152(55)$ & Six months & 16 of $56(28)$ \\
\hline Greater than three years & 31 of 165 (19) & One year & 53 of $152(35)$ & Other & 1 of $56(2)$ \\
\hline Other & 1 of $165(0.6)$ & Greater than two years & 5 of $152(3 \%)$ & & \\
\hline
\end{tabular}

*Some physicians did not respond to all questions. BE Barrett's esophagus; HGD High grade dysplasia; LGD Low grade dysplasia 
TABLE 4

Endoscopic biopsy protocol used by physicians for patients with Barrett's esophagus*

\begin{tabular}{lc}
\hline Biopsies & $\mathbf{n}$ of $\mathbf{1 5 1}$ respondents (\%) \\
\hline Four quadrant biopsies taken at & $20(13)$ \\
$1 \mathrm{~cm}$ intervals & $69(46)$ \\
$2 \mathrm{~cm}$ intervals & $11(7)$ \\
Greater than $3 \mathrm{~cm}$ intervals & $8(5)$ \\
No specified intervals & $5(3)$ \\
Random biopsies & $23(15)$ \\
No protocol followed & $15(10)$ \\
Other &
\end{tabular}

*14 respondents did not answer this question

have not been proven to be more beneficial than every two years. Whether screening patients with $\mathrm{BE}$ with regular endoscopy is cost effective is also unproven, although it is the current standard of practice. One recent prospective study (28) evaluated 143 patients with BE undergoing yearly screening over 10 years, and found that only one cancer was detected as a result of the surveillance program. Esophageal adenocarcinomas developed in a total of five individuals, but was detected during an unscheduled endoscopy for worsening symptoms in two patients, and in two patients who had defaulted from the program.

An economic study of endoscopic screening for BE found that yearly endoscopies would cost an estimated US\$62,000 (in 1988) and $78 \mathrm{~h}$ of lost work-days to discover one cancer during the screening process (9). The authors recommended screening every two years to reduce cost. A more recent economic modelling study found that yearly surveillance was the best choice if only length of life is considered (21). However, when quality of life and life expectancy were both considered, two to three year intervals were recommended (21).

There is concern that the risk of developing adenocarcinoma has been overestimated and, consequently, the intervals between endoscopies can be increased. A study by Shaheen et al. (10), which looked at 27 publications, found that reporting a higher risk of cancer was related to study size, the definition of $\mathrm{BE}$, and the nature of the study (retrospective versus prospective), supporting publication bias.
Esophageal adenocarcinoma progresses through well defined histological stages, described as the metaplasia-dysplasiacarcinoma sequence $(29,30)$. The increased risk of developing cancer in patients with low grade dysplasia is reflected in the published guidelines that recommend surveillance increase to every six months. After one year without worsening histology, the surveillance can extend to yearly intervals $(18-20)$. The concern about low grade dysplasia progressing to malignancy is reflected in this survey, with $55 \%$ of respondents screening every six months, and $35 \%$ performing yearly screening for patients with low grade dysplasia.

The published guidelines recommend that patients with confirmed high grade dysplasia, who are surgically fit, undergo esophageal resection (18-21). Approximately $50 \%$ of patients with high grade dysplasia will be found to have unsuspected invasive adenocarcinoma $(31,32)$. Recent studies have suggested that surgery can be delayed in patients with high grade dysplasia although this is not the current standard of care $(32,33-36)$. The majority $(81 \%)$ of Canadian gastroenterologists indicate that they refer patients with high grade dysplasia for surgery. Although some physicians reported continued surveillance of patients with high grade dysplasia, or alternative therapy, there is overlap with these numbers because 11 of 165 (7\%) respondents checked all three options, suggesting that these options are patient-dependent. For example, an elderly person who is medically at high risk for surgery may be referred for endoscopic ablation therapy.

Detection of high grade dysplasia and unsuspected adenocarcinoma are the main reasons for standardized biopsy protocols $(36,37)$. Most guidelines recommend four-quadrant biopsies at $2 \mathrm{~cm}$ intervals (18-20). Boyer and Robaszkiewiez (20) recommend $1 \mathrm{~cm}$ intervals for $\mathrm{BE}$ segments shorter than $3 \mathrm{~cm}$. Biopsy protocols were quite variable in this survey, ranging from four-quadrants every $2 \mathrm{~cm}(46 \%)$ to $15 \%$ of respondents who said they did not follow any biopsy protocol. It is likely that this in part is due to patients with short segment $\mathrm{BE}$ where a standardized biopsy protocol is not possible.

Although the ACG recommends that patients with chronic GERD should have an endoscopy to screen for BE (18), no timing was specified. This survey demonstrates that Canadian gastroenterologists agreed with this statement, as $76 \%$ said they believe in 'once in a lifetime' endoscopy for patients with chronic GERD. They also indicated that criteria for endoscopy

\section{TABLE 5}

Physician's opinions of once in a lifetime endoscopies for patients with longstanding gastroesophageal reflux disease

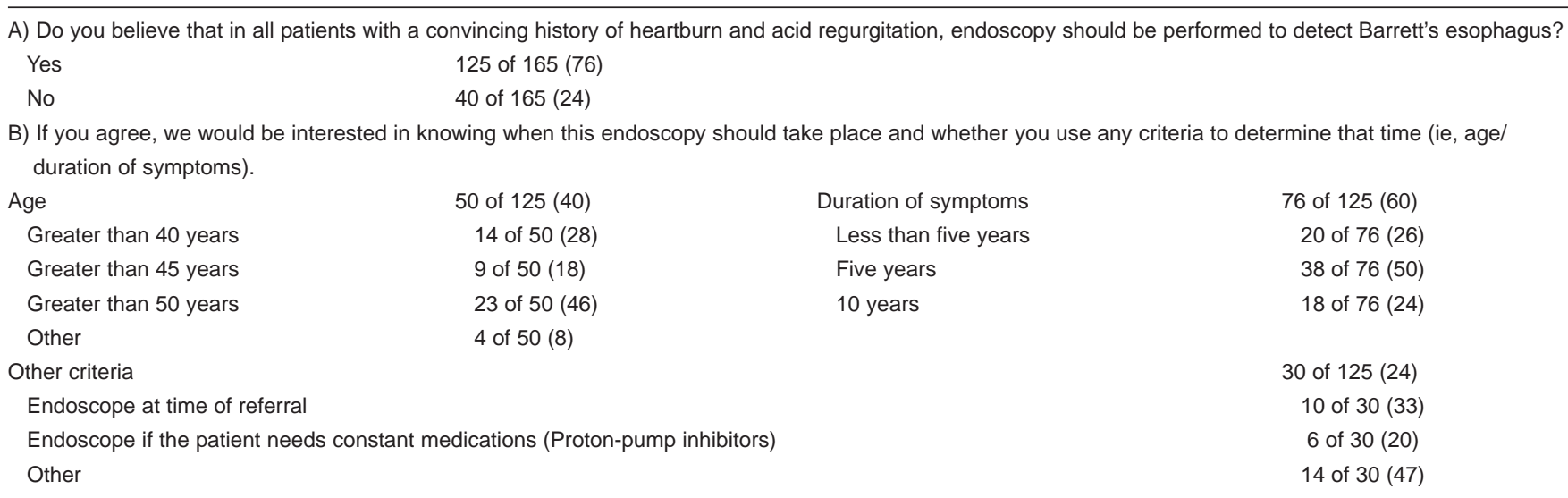


should include duration of symptoms (61\%) and age (40\%). However, the optimal timing and criteria for 'once in a lifetime' endoscopy warrants further critical study before evidence based recommendations can be given. Large forceps biopsies are recommended to get adequate biopsy samples.

The results of the present survey may not reflect the opinions of all Canadian gastroenterologists as the response was $68 \%$. However, we found that the majority of Canadian gastroenterologists who responded to the survey followed the published guidelines, and indicated support for a 'once in a lifetime' endoscopy. Future advances in understanding the molecular pathogenesis of $\mathrm{BE}$ and esophageal adenocarcinoma may further modify endoscopic surveillance for this disease in the future (38).

\section{REFERENCES}

1. Eisen GM, Sandler RS, Murray S, Gottfried M. The relationship between gastroesophageal reflux disease and its complications with Barrett's esophagus. Am J Gastroenterol 1997;92:27-31.

2. Lagergren J, Bergstrom R, Lindgren A, Nyrén O. Symptomatic gastroesophageal reflux as a risk factor for esophageal adenocarcinoma. N Engl J Med 1999;340:825-31.

3. Cameron AJ, Zinsmeiser AR, Ballard DJ, Carney JA. Prevalence of columnar-lined (Barrett's) esophagus. Gastroenterology 1990;99:918-22.

4. Splechler ST. Barrett's esophagus. N Engl J Med 2002;346:836-42.

5. Hameeteman W, Tytgat GNJ, Houthoff HJ, van den Tweel JG. Barrett's esophagus: Development of dysplasia and adenocarcinoma. Gastroenterology 1989;96:1249-56.

6. Drewitz DJ, Sampliner RE, Garewal HS. The incidence of adenocarcinoma in Barrett's esophagus: A prospective study of 170 patients followed 4.8 years. Am J Gastroenterol 1997;92:212-5.

7. Miros M, Kerlin P, Walker N. Only patients with dysplasia progress to adenocarcinoma in Barrett's esophagus. Gut 1991;32:1441-6.

8. Ferraris R, Bonelli L, Conio M, et al. Incidence of Barrett's adenocarcinoma in an Italian population: An endoscopic surveillance programme. Eur J Gastroenterol Hepatol 1997;9:881-5.

9. Achkar E, Carey W. The cost of surveillance for adenocarcinoma complicating Barrett's esophagus. Am J Gastroenterol 1988;83:291-4.

10. Shaheen NJ, Crosby MA, Boyzmski EM, Sandler RS. Is there publication bias in the reporting of cancer risk in Barrett's esophagus? Gastroenterology 2000;119:333-8.

11. Byter P, Christensen PB, Damkier P, Vinding K, Seersholm N. Adenocarcinoma of the esophagus and Barrett's esophagus: A population-based study. Am J Gastroenterol 1999;94:86-91.

12. Blot WJ, Devesa SS, Kneller RW, Fraumeni JF. Rising incidence of adenocarcinoma of the esophagus and gastric cardia. JAMA 1991;265:1287-94.

13. Farrow DC, Vaughan TL. Determinants of survival following the diagnosis of esophageal adenocarcinoma (United States). Cancer Causes Control 1996;7:322-7.

14. Steup WH, De Leyn P, Deneffe G, Van Raemdonck D, Coosemans W, Lerut T. Tumors of the esophagogastric junction. Long-term survival in relation to patterns of lymph node metastasis and a critical appraisal of the accuracy or inaccuracy of pTNM classification. J Thorac Cardiovasc Surg 1996;111:85-95.

15. Ellis FH, Heatley GJ, Krasna MJ, Williamson WA, Balogh K. Esophagogastrectomy for carcinoma of the esophagus and cardia: A comparison of findings and results after standard resection in three consecutive eight-year intervals with improved staging criteria. J Thorac Cardiovasc Surg 1997;113:836-48.

16. Casson AG, Tammemagi M, Eskandarian S, et al. p53 alterations in esophageal cancer: Association with clinicopathologic features and survival. Mol Pathol 1998;51:71-9.
17. Streitz JM, Andrews CW, Ellis FH. Endoscopic surveillance of Barrett's esophagus. Does it help? J Thorac Cardiovasc Surg 1993;105:383-8

18. Sampliner RE, The Practice Patterns Committee of the American College of Gastroenterology. Practice guidelines on the diagnosis, surveillance, and therapy of Barrett's esophagus. Am J Gastroenterol 1998;93:1028-32.

19. Beck IT, Champion MC, Lemire S, et al. The second Canadian consensus conference on the management of patients with gastroesophageal reflux disease. Can J Gastroenterol 1997;11(Suppl B):7B-20B.

20. Boyer J, Robaszkiewiez M. Guidelines of the French Society of Digestive Endoscopy: Monitoring of Barrett's esophagus. The Council of the French Society of Digestive Endoscopy. Endoscopy 2000;32:498-9.

21. Provenzale D, Kemp JA, Arora S, Wong JB. A guide for surveillance of patients with Barrett's esophagus. Am J Gastroenterol 1994;89:670-80.

22. Falk GW, Ours TM, Richter JE. Practice patterns for the surveillance of Barrett's esophagus in the United States. Gastrointest Endosc 2000;52:197-203.

23. Gross CP, Canto MI, Hixson J, Powe NR. Management of Barrett's esophagus: A national study of practice patterns and their cost implications. Am J Gastroenterol 1999;94:3440-7.

24. van Sandick JW, Bartelsman JFWM, van Lanschot JJB, Tytgat GNJ, Obertop H. Surveillance of Barrett's oesophagus: Physicians' practices and review of current guidelines. Eur J Gastroenterol Hepatol 2000;12:111-7.

25. Smith AM, Maxwell-Armstrong CA, Welch NT, Scholefield JH. Surveillance for Barrett's oesophagus in the UK. Br J Surg 1999;276-80.

26. Sharma P, Weston A, Falk G, Johnston M, Reker D, Sampliner R. Can two upper endoscopies negative for dysplasia eliminate the need for future surveillance in patients with Barrett's esophagus? Am J Gastroenterol. 2001;96(Suppl):S36. (Abst)

27. Sampliner RE, Practice Parameters Committee of ACG. Updated guidelines for the diagnosis, surveillance, and therapy of Barrett's esophagus. Am J Gastroenterol 2002;97:1888-95.

28. Macdonald CE, Wicks AC, Playford RJ. Final results from 10 year cohort of patients undergoing surveillance for Barrett's Esophagus: Observational study. BMJ 2000;321:1252-5.

29. Jankowski J, Wright NA, Meltzer S, et al. Molecular evolution of the metaplasia-dysplasia-adenocarcinoma sequence in the esophagus. Am J Pathol 1999;154:965-73.

30. Splechler SJ. Disputing dysplasia. Gastroenterology 2001;120:1864-8.

31. Heitmiller RF, Redmond M, Hamilton SR. Barrett's Esophagus with high-grade dysplasia: An indication for prophylactic esophagectomy. Ann Surg 1996;224:66-71.

32. Zaninotto G, Parenti AR, Ruol A, Constantini S, Ancona E. Oesophageal resection for high-grade dysplasia in Barrett's oesophagus. Br J Surg 2000;87:1102-5.

33. Buttar N, Wang KK, Sebo TJ, et al. Extent of high-grade dysplasia in Barrett's Esophagus correlates with risk of adenocarcinoma. Gastroenterology 2001;120:1630-9.

34. Schnell TG, Sontag SJ, Chejfec G, et al. Long-term nonsurgical management of Barrett's Esophagus with high-grade dysplasia. Gastroenterology 2001;129:1607-19.

35. Weston AP, Sharma P, Topalovski M, Richards R, Cherian R, Dixon A. Long-term follow-up of Barrett's high grade dysplasia. Am J Gastroenterol 2000;95:1888-93.

36. Levine DS, Haggitt RC, Blount PL, Rabinovitch PS, Rusch VW, Reid BJ. An endoscopic biopsy protocol can differentiate highgrade dysplasia from early adenocarcinoma in Barrett's Esophagus. Gastroenterology 1993;105:40-50.

37. Reid BJ, Blount PL, Feng Z, Levine DS. Optimizing endoscopic biopsy detection of early cancers in Barrett's high-grade dysplasia. Am J Gastroenterol 2000;95:3089-95.

38. Casson AG. Role of molecular biology in the follow-up of patients who have Barrett's esophagus. Chest Surg Clin N Am 2002;12:93-111. 


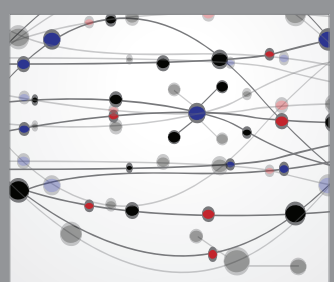

The Scientific World Journal
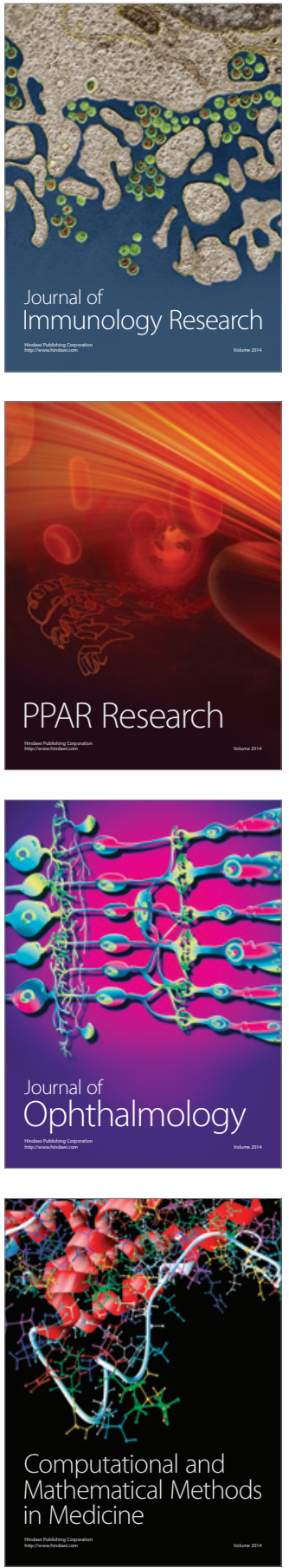

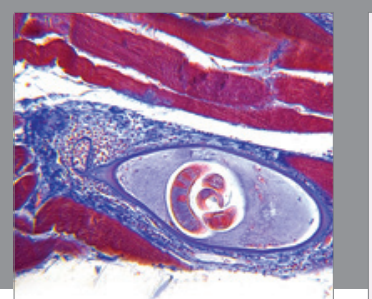

Gastroenterology Research and Practice

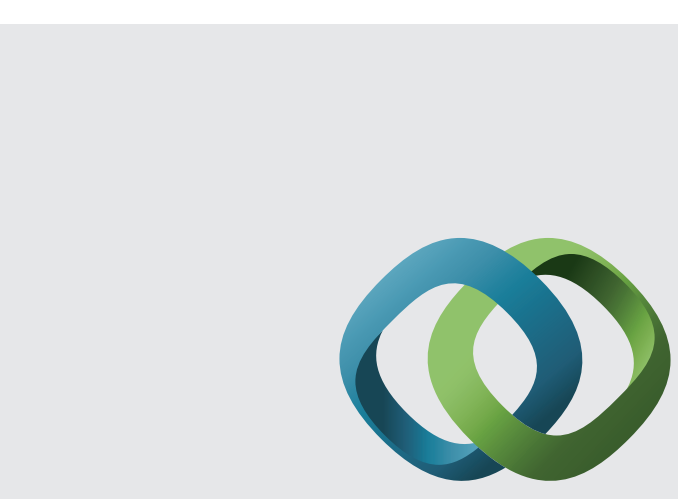

\section{Hindawi}

Submit your manuscripts at

http://www.hindawi.com
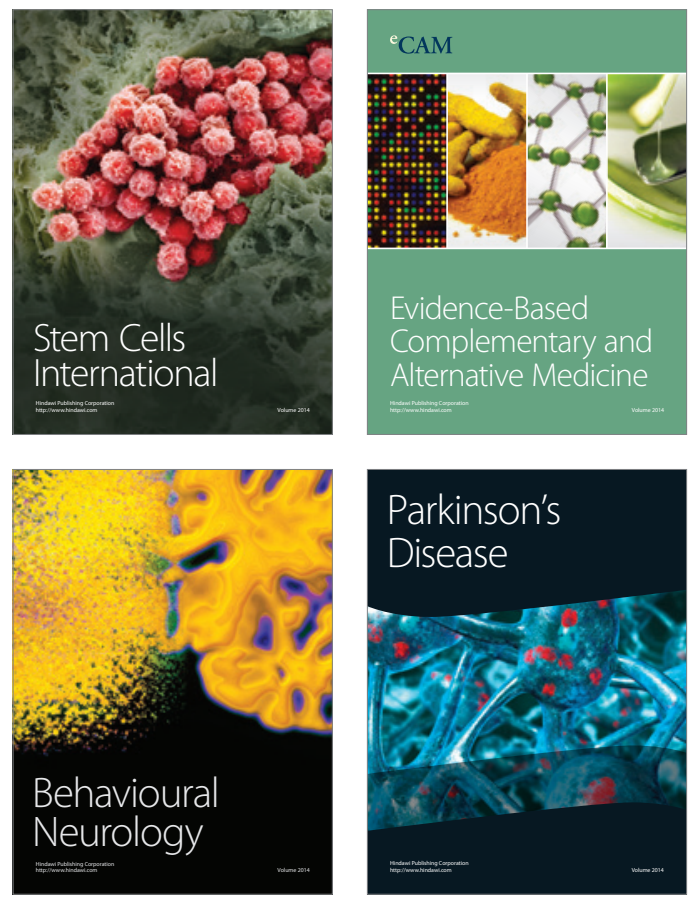
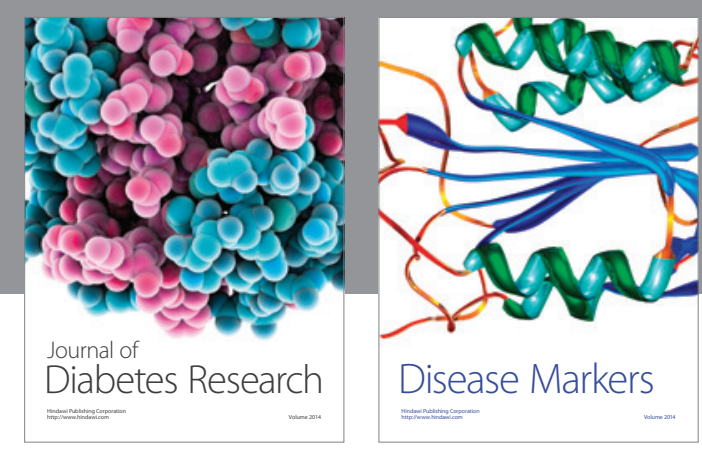

Disease Markers
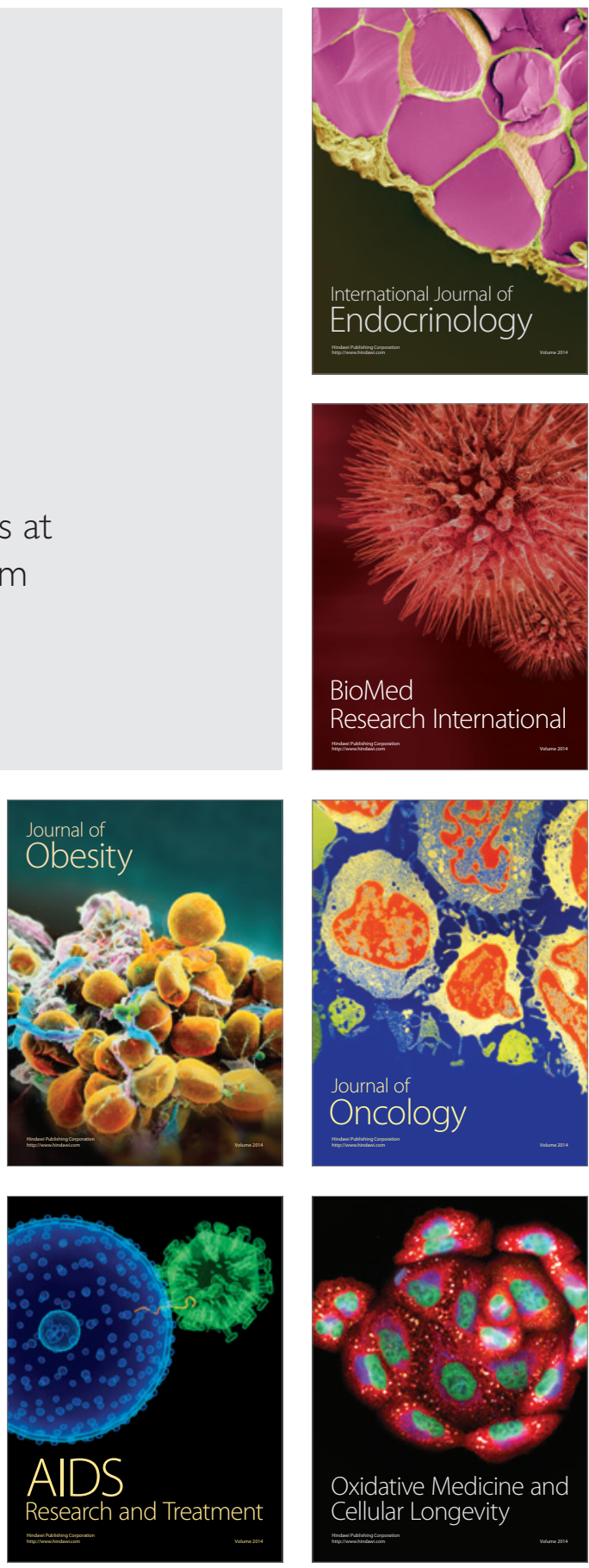